\title{
LITERATURA CARCERÁRIA: EDUCAÇÃO SOCIAL POR MEIO DA EDUCAÇÁO, DA ESCRITA E DA LEITURA NA PRISÃO
}

\author{
CARCERARY LITERATURE: SOCIAL EDUCATION THROUGH \\ EDUCATION, WRITING AND READING IN PRISON
}

\begin{abstract}
Roberto da Silva Professor livre docente do Departamento de Administração Escolar e Economia da Educação da Faculdade de Educação da Universidade de São Paulo. São Paulo - SP- Brasil ORCID: https://orcid.org/0000-001-8195-8664 kalil@usp.br

Thais Barbosa Passos

Doutoranda em Educação pelo Programa de Pós-Graduação da Faculdade de Educação da Universidade de São Paulo. São Paulo - SP- Brasil ORCID: https://orcid.org/0000-0003-3093-240X thabpassos@usp.br

Marineila Aparecida Marques Mestranda em Educação pelo Programa de Pós-Graduação da Faculdade de Educação da Universidade de São Paulo. São Paulo - SP- Brasil ORCID: https://orcid.org/0000-0002-3842-0401 marineila.marques@educacao.sp.gov.br
\end{abstract}

Resumo: $\mathrm{O}$ artigo, que trata de problema de pesquisa investigado pelo GEPÊPRIVAÇÃO e seus pesquisadores, com orientaçáo do Prof. Dr. Roberto da Silva, na Faculdade de Educação da USP, visa a caracterização da literatura carcerária desenvolvida sob a égide da alfabetização de adultos e da recente regulamentação da Educação em Prisóes, considerando as transformaçôes e adaptaçóes ao longo dos tempos. Além da discussão teórica e conceitual, o artigo apresenta, a título de exemplo, livros escritos por presos e presas, agentes penitenciários, professores e juízes como a nova dimensão dessa literatura carcerária. $\mathrm{O}$ artigo recorre à Teoria do Reconhecimento, de Axel Honneth, e à literatura de testemunho, de Márcio Seligmann-Silva, para embasar seus argumentos.

Palavras-chave: Cartas-Denúncia. Educação Prisional. Literatura Carcerária. Literatura de Testemunho. Teoria do Reconhecimento.

Aвstract: The article, which deals with a research problem investigated by the GEPÊPRIVAĀO (Research Group on Education in Deprivation of Liberation Regimes) and its researchers, with the guidance of Prof. Dr. Roberto da Silva, at the School of Education of USP, aims to characterize the prison literature developed under the aegis of adult literacy and the recent regulation of Prison Education considering the transformations and adaptations over time. Besides the theoretical and conceptual discussion, the article presents, by way of example, books written by prisoners and prisoners, penitentiary agents, teachers and judges as the new dimension of this prison 
literature. The article uses Axel Honneth's Theory of Recognition and the testimony literature of Márcio Seligmann-Silva to support his arguments.

Keywords: Letters of Complaint; Prison Education; Prison Literature. Testimonial Literature. Theory of Recognition.

\section{Introduçáo}

A título de registro e de resgate histórico revisitamos seis produçóes que nos auxiliam a contextualizar historicamente, no tempo e no espaço a produção que nos interessa para este artigo.

$\mathrm{O}$ primeiro registro refere-se à tese de doutoramento de Eliane Leal Vasquez, defendida na PUC/SP em 2013, com o título Ciência Penitenciária no Brasil Império: disciplinar para construir a imagem de nação civilizada, na qual ela registra os esforços de D. Pedro II para inserir o Brasil na nascente discussão internacional sobre ciência penitenciária. Vasquez cita o filantropo John Howard $(1720$ - 1796) e sua obra State of the prisons in England and Wales como o marco inicial da "literatura penitenciária”, mas deixando bem claro que esta nomenclatura designa então o ramo de estudos que serão desenvolvidos pelos chamados "penitenciaristas”, sejam eles oriundos da escola clássica (Beccaria, século XVIII), escola positiva (Lombroso, século XIX) ou da escola sociológica (final do século XIX). Em solo brasileiro esta vertente prosperou no sentido da criação de leis, normas, regulamentos e normatização de procedimentos para operaçôes de prisóes e controle de presos, podendo ser modernamente entendida como Direito Penitenciário.

O segundo estudo é a tese de doutoramento de Ovídio Poli Junior, defendida em 2009 na Faculdade de Filosofia, Letras e Ciências Humanas da Universidade de São Paulo sob o título A pena e o cadafalso: observaçôes sobre a literatura carcerária relativa ao período do Estado Novo. No âmbito do período estudado - 1937 a 1945 - Poli Junior focaliza a atenção na "literatura carcerária brasileira escrita no cárcere ou sob a forma de reminiscências", mas de "caráter ficcional, epistolar e memorialístico" versando "sobre como os autores operaram em suas obras as representaçóes do cárcere" [...] como refletiram sobre o universo carcerário e como o recriaram enquanto matéria literária." (2009, p. 7) Desse período ele cita Graciliano 
Ramos, Jorge Amado, Dyonélio Machado, Barão de Itararé e Monteiro Lobato, todos autores consagrados na literatura nacional.

O terceiro estudo que nos interessou refere-se à produção de Maria Salete Van Der Poel, professora aposentada da Universidade Federal da Paraíba, fundadora da Rede de Letramento da Paraíba (RELEJA), por meio da qual desenvolveu práticas de Educação de Jovens e Adultos em prisóes do seu estado natal. Tendo trabalhado com Paulo Freire, publicou, como resultado de suas experiências pedagógicas, o livro Alfabetização de adultos. Sistema Paulo Freire: Estudo de Caso num presidio (1981).

Em continuação a essa obra pioneira, publicou em 2018 o livro Vidas aprisionadas: relatos de uma prática educativa, historiando o processo de alfabetização de presos em pleno regime militar no Brasil. Oportuno relembrar que o próprio Paulo Freire esteve preso em Recife e Olinda por setenta dias, antes de ser enviado para o exílio no exterior. Mais adiante vamos ressaltar a relevância que teve e que tem a alfabetização de presos, a elevação de sua escolaridade e as práticas da escrita dentro da prisão como nova matriz de uma literatura carcerária genuinamente produzida por presos comuns, seus professores e alunos, assim como agentes penitenciários e operadores do Direito.

O quarto estudo de interesse foi produzido a pedido do Ministério da Educação e da Organização dos Estados Ibero Americanos (OEI) e tem como autor Fábio Aparecido Moreira, também integrante do GEPÊPRIVAÇÃO. Sua pesquisa, intitulada Açóes de incentivo à leitura e formação de leitores em estabelecimentos prisionais do Brasil: desafios e oportunidades, investigou a prática da leitura nos estados de São Paulo, Paraná, Rio de Janeiro, Mato Grosso do Sul e Brasília, já sob a égide dos marcos regulatórios que reconheceram tanto a educação quanto a leitura como fatores de redução da pena. Fábio concluiu pelo uso ainda meramente instrumental da leitura e da escrita, objetivando primordialmente a redução de dias na sentença de condenação, com pouca ênfase no desenvolvimento das competências leitoras e escritoras e menos ainda na preparação de leitores e de escritores.

Também em sede de doutoramento, desta feita na Unicamp em 2017, Eli Narciso Torres defendeu a tese intitulada $A$ gênese da remição de pena pelo estudo: o dispositivo jurídico-político e a garantia do direito à educação aos privados de liberdade no Brasil, na qual ela não apenas historiciza 
a implementação da remição da pena pelos estudos e pela leitura no Brasil, como também apresenta dados em relação ao seu estado de origem - Mato Grosso do Sul -, discorrendo sobre as motivaçóes, os principais atores e o processo de implantação destas práticas no sistema prisional brasileiro.

O sexto e último estudo a ser relembrado nesta Introdução é denominado Cartas do Cárcere, patrocinado pelo Departamento Penitenciário Nacional (DEPEN), que franqueou, por meio de edital público, um acervo de 8.818 cartas enviadas por presos e seus familiares à Ouvidoria Nacional dos Serviços Penais (ONSP). Coordenado por Thula Rafaela de Oliveira Pires, da Pontifícia Universidade Católica do Rio de Janeiro (PUC/RJ), pela primeira vez na história do sistema prisional brasileiro cartas escritas por presos e seus familiares às autoridades, órgãos e serviços públicos receberam tratamento acadêmico e editorial, sinalizando aos pesquisadores que cartas como essas devam também ser consideradas como parte da literatura carcerária.

\section{O direito de petiçáo como direito de autoria da própria vida e da própria história}


independentemente do pagamento de taxas: a) o direito de petiçáo aos Poderes Públicos em defesa de direitos ou contra ilegalidade ou abuso de poder" (grifo nosso); e nos termos do Artigo 41 da Lei de Execução Penal, constituem direitos do preso, dentre outros:

XIV - representação e petição a qualquer autoridade, em defesa de direito;

$\mathrm{XV}$ - contato com o mundo exterior por meio de correspondência escrita, da leitura e de outros meios de informação que não comprometam a moral e os bons costumes.

Tais direitos são efetivados no sistema prisional brasileiro por meio de correspondências dirigidas, principalmente, à Ouvidoria vinculada ao órgão mais diretamente responsável pela administração penitenciária, seja em nível nacional ou nível estadual. Segundo o Regimento Interno da Ouvidoria Nacional dos Serviços Penais (ONSP), e que serve de parâmetro para se entender as competências das ouvidorias estaduais, ela é um órgão vinculado ao Sistema Prisional que tem como objetivos primordiais:

A defesa dos direitos das pessoas privadas de liberdade e seus familiares, o acolhimento e processamento de manifestaçôes e denúncias de servidores, o fortalecimento do controle e participação social nos serviços penais e, ainda, o monitoramento dos estabelecimentos penais do país, a partir de inspeçôes prisionais. (PORTARIA MJ n ${ }^{\circ}$ 5, de 4 de janeiro de 2018)

As ouvidorias do sistema prisional são, portanto, os órgãos receptores das cartas encaminhadas por presos e seus familiares, seja no sentido de fazer denúncias, reivindicaçôes ou solicitação de providências de qualquer órgão ou serviço da administração pública.

Não há estatísticas oficiais sobre o número de cartas que chegam às Ouvidorias originárias do sistema prisional. Entretanto, a Convocação no 1/2017 - Projeto BRA/14/011 do Ministério da Justiça, por meio da qual o DEPEN colocou em concorrência pública parte do seu acervo de cartas, indicou 8.818 dirigidas ao órgão federal só no ano de 2016. Como temos 26 estados e um Distrito Federal, portanto, 27 outros sistemas prisionais, 
que somam cerca de duas mil unidades prisionais com cerca de $730 \mathrm{mil}$ presos, a maioria deles em condiçóes irregulares, dá para imaginar o tamanho do problema a que estamos nos referindo neste artigo, que assume materialidade em cartas escritas por presos e seus familiares às ditas 'autoridades competentes'.

Do ponto de vista do registro, processamento, guarda e destinação final das cartas recebidas pelas ouvidorias prevalece o entendimento da Lei $\mathrm{N}^{\circ} 8.159$, de 8 de Janeiro de 1991, que dispóe sobre a política nacional de arquivos públicos e privados e dá outras providências, que impõe a todos os estados e municípios a obrigatoriedade de um Plano de Classificação de Documentos e estipula períodos para o descarte de documentos.

\section{A produçáo literária na prisáo}


a nossa atitude diante desse monstro chamado Público." O mesmo autor coloca a dúvida formulada por Sophia Angelides: "Pode ser a carta lida e usufruída como obra de literatura, ou constitui apenas um material auxiliar para o conhecimento de seu autor, de problemas relacionados com a sua obra, de suas concepçóes e de seu ambiente social?"

Para dirimir esta questão e explicitar a posição que os atores defendem neste artigo recorremos a dois outros autores: Márcio SeligmannSilva e Alex Honneth.

$\mathrm{Na}$ obra Luta por reconhecimento: a gramática moral dos conflitos sociais, Alex Honneth (2003), tratando, principalmente, da explicação teórica e crítico-normativa das relaçóes de poder, respeito e reconhecimento, mostra como indivíduos e grupos sociais se inserem na sociedade atual. Para ele, a inserçáo do indivíduo no sistema prisional reforça a representação de papéis sociais que assumirão formas específicas de subjetivação. Ao indivíduo preso é reservada a manifestação de, basicamente, dois tipos de identidade, a saber: a institucional e a de bandido, ambas caracterizadas pela situação de exclusão do indivíduo do meio social mais amplo. Segundo Honneth (2003), há também três formas de reconhecimento, a saber: o amor, o direito e a solidariedade. A luta pelo reconhecimento sempre inicia pela experiência do desrespeito dessas formas de reconhecimento. A autorrealização do indivíduo somente é alcançada quando há, na experiência de amor, a possibilidade de autoconfiança, na experiência de direito, o autorrespeito e, na experiência de solidariedade, a autoestima. Portanto, para Honneth as mudanças sociais ocorrem por meio da luta por reconhecimento. Assim, ele propôe uma concepção normativa de eticidade a partir de diferentes dimensóes de reconhecimento, afirmando que os indivíduos e os grupos sociais somente podem formar a sua identidade quando forem reconhecidos intersubjetivamente.

Quem conhece o meio prisional, mesmo sem nunca ter tido acesso a alguma dessas cartas a que estamos nos referindo, pode deduzir com razoável clareza os conteúdos das que são dirigidas às autoridades. SeligmannSilva (2003), ao caracterizar cartas como 'literatura de testemunho' afirma que essa abordagem privilegia o conteúdo humano implícito nessa temática, a percepçáo que o indivíduo tem da execução penal no Brasil, os fatos que relata, a representação que tem das instituiçóes republicanas, dos seus agentes e de suas práticas, o que nos dará elementos para avaliar o grau 
de efetividade da política criminal e penitenciária no Brasil em um dado momento histórico.

Originária de registros de grandes dramas pelos quais a humanidade passou, como as guerras mundiais, o holocausto, os genocídios e outras atrocidades, não são poucos os autores que se ocupam dessa abordagem, como não são poucas as obras que se prestam a este tipo de abordagem. ${ }^{1}$ Resgatando testemunhos de alguns relatos de sobreviventes dos campos de extermínio especialmente o de Primo Levi, no livro O que resta de Auschwitz, o filósofo italiano Giorgio Agamben é um desses expoentes. Paul Ricoeur (2007, p. 170-175), no capítulo intitulado "O testemunho", de seu livro $A$ memória, a história, o esquecimento, explora o uso jurídico e o uso histórico do termo testemunho, e desdobra seis "componentes essenciais" da operação testemunhal. Roberto da Silva, coordenador do GEPÊPRIVAÇÃO, tendo passado parte de sua vida em abrigos, Febens e sistema penitenciário, recupera a historicidade das instituições de atendimento no Brasil, especialmente durante a vigência do Regime Militar no Brasil. (SILVA, 1997)

\section{A literatura carcerária como novidade editorial}

\section{Agentes penitenciários}

Há um número expressivo de trabalhadores do sistema prisional, em todos os estados brasileiros, que publicaram livros. Escolhemos alea-

Muito influenciado pelas experiências de alfabetização em prisões, beneficiado pelos efeitos positivos da universalização da Educação e fortemente estimulados pela possibilidade de diminuiçáo das penas por meio do estudo e da leitura, prosperam no Brasil, de um lado, esforços para dotar as prisóes de bibliotecas, para criar projetos de incentivo à leitura, de estudos e pesquisas sobre a Educação e a leitura na prisão, e, de outro lado, de oficinas de criação literária, que têm em vista dar voz ao próprios presos, aos agentes penitenciários, aos seus educadores e aos operadores do próprio sistema prisional. É a esta nova produção que reservamos, neste artigo, o uso do termo literatura carcerária, das quais citamos alguns exemplos. 
toriamente alguns exemplos para ilustrar este artigo, mas fica registrado o nosso reconhecimento a esses agentes penitenciários que fazem muito mais do que abrir e fechar celas.

Marcelo Otávio de Souza ${ }^{3}$, dracenense que trabalha como agente penitenciário há cerca de 15 anos, publicou três livros de poesia com o pseudônimo Marc Souza. Fatos, relatos, boatos (Redondeza Contos, 2014), Casos, acasos e descasos - várias, variáveis de uma vida sem graça (Aped, 2015), Balaio de gatos (Clube de Autores, 2018). Ainda que seus livros não tratem diretamente do cotidiano da prisão, têm em vista o potencial da leitura para a transformação da realidade em que vive e trabalha. Ele direciona seus escritos também aos agentes penitenciários por meio de uma coluna mensal no site do sindicato ao qual é filiado. Esse é um caso em que não sabemos se é um escritor que se tornou agente penitenciário ou se é um agente penitenciário que se tornou escritor.

Anderson Gimenes, inspirado no rap Diário de um detento, dos Racionais MC's, escreveu Diário de um agente de segurança penitenciária $(2015)^{4}$, no qual relata 8 anos da história de um jovem que, durante seu processo de formação em Licenciatura plena em Geografia, por dificuldades financeiras, após prestar e ser aprovado em concurso público, abandonou a tudo e a todos e partiu rumo à Grande São Paulo, para exercer a sua nova profissão: Agente de Segurança Penitenciária. No novo ambiente se mostrou, de início, em pânico e um ignorante no assunto, mas no dia a dia obteve experiência profissional que hoje lhe permite ser um crítico do sistema carcerário, de sua administração pública comissionada e do governo do estado de São Paulo; por ser também alguém que consegue indicar métodos para a solução dos problemas citados, mostrando sempre a realidade, com uma pitada da história pessoal desse profissional tão necessário e tão pouco valorizado pela sociedade e pelo Estado.

\section{Juízes e promotores}

João Marcos Buch definitivamente não é um juiz convencional. Nascido em Porto União, no Norte do Estado, virou juiz aos 23 anos. De lá para cá, foram mais de duas décadas de sentenças, parte delas marcada por fortes opinióes e interpretaçóes consideradas tabus 
pela Justiça. A postura gera críticas de colegas do Judiciário, repulsa de membros das forças de segurança e o coloca como um dos magistrados mais polêmicos de Santa Catarina. E não é por menos. Buch já mandou prender diretor de presídio, condenou políticos do primeiro escalão, chamou secretários de Estado de incompetentes e náo poupou frases de efeito, como quando comparou o Presídio Central de Porto Alegre a um campo de concentração.

Suas opinióes, posicionamentos e os relatos de suas experiências estão nos sete livros que já publicou: Juiz de si, Juiz do mundo; A esperança persiste; Crônicas, relatos e vivências; Retroceder jamais; Diário de bordo de um juiz das causas humanas; Juiz achado na rua; Tortura e prisioneiros e juizes: relatos do cárcere. A crônica é o gênero sempre dominante de seus escritos, todos publicados pela Giostri Editora, sua parceira no fomento à leitura nos presídios de Santa Catarina. No livro Prisioneiros e juizes: relatos do cárcere há relatos de 8 presos de uma unidade prisional de Joinville, Santa Catarina, que são frutos de atividades literárias propostas pelo editor Alex Giostri e pelo Juiz Corregedor do Complexo Prisional da Comarca de Joinville, João Marcos Buch,.

Os presos foram convidados a apresentar voluntariamente seus relatos pessoais a fim de que cada um fosse levado a um juiz convidado e cada Juiz a fazer um texto próprio e independente a partir do relato que leu, sempre pensando as questóes do sistema penal como o desencarceramento e, sobretudo, nas questóes sociais, educacionais e de estrutura familiar, questôes que são pilares responsáveis, evidentes e escancarados, do atual quadro dos mais de 720 mil encarcerados no Brasil.

\section{Professores e educadores}

Por causa de seu pioneirismo, trazemos de volta Maria Salete van der Poel e seu livro mais atual - Vidas aprisionadas: relatos de uma prática educativa (Oikos, 2018). Maria Salete nasceu em Campina Grande, na Paraíba, na família Agra, uma das mais tradicionais daquela cidade. $\mathrm{Na}$ década de 1960 atuou na Juventude Estudantil Católica, na Juventude Universitária Católica e na Campanha de Educação Popular da Paraíba (Ceplar) alfabetizando jovens, adultos, presidiários e prostitutas, o que 
lhe custou perseguiçóes pelo regime militar. Professora aposentada da UFPB, ela atua na Educaçáo de Jovens e Adultos com a Rede de Letramento da Paraíba (Releja), fundada por ela e seu marido, Cornelis Van de Pöel.

O pioneirismo atribuído a ela se deve à publicação do livro Alfabetização de Adultos. Sistema Paulo Freire. Estudo de caso num Presídio (Vozes, 1981). Como integrante da Campanha de Educação Popular da Paraíba (CEPLAR), no começo da década de 60, aplicou o Sistema Paulo Freire de Educação de Adultos. Em seguida, adaptou esse método de alfabetização conscientizadora a clientelas específicas: crianças e adolescentes de vários educandários de Campina Grande e, depois, em prisóes masculinas e femininas.

O registro minucioso de Van der Poel, nos moldes de um diário de campo, descrevem o dia a dia de trabalho de uma professora dentro da prisão que não se limita a ensinar a ler e escrever. Esse tipo de testemunho é a evidência mais cabal de que a gênese da literatura carcerária enquanto produção de seus próprios atores tem na alfabetização de adultos presos a sua gênese e motivação. Envolvida nas práticas de educação popular e tendo trabalhado com o próprio Paulo Freire, procurou construir um método de alfabetização que não somente permitisse aos indivíduos aprenderem a ler, escrever e contar, mas que, ainda, lhes proporcionasse a construção de uma consciência crítica, a fim de que pudessem se tornar construtores da sua própria história.

Apenas para dar uma dimensão do que significa o pioneirismo dessa autora, transcrevemos abaixo um trecho do livro Vidas aprisionadas, que possivelmente remeta ao primeiro estudo acadêmico sobre o significado da obra de Paulo Freire para a Educação em Prisões:

Não vou convocar o Conselho do Mestrado para marcar a data da sua defesa, porque, enquanto eu for coordenador deste mestrado você não defenderá essa dissertação. Trata-se de assunto que pode prejudicar o reconhecimento do Mestrado. E você sabia e sabe o período de uma teser que tem como fundamento Paulo Freire, autor quer, até hoje, permanece no exílio e foi "fichado como comunista e subversivo". Não vou colocar em risco o reconhecimento do Mestrado no momento e que está 
nos últimos trâmites. Procure fazer um outro trabalho. Este você não defenderá. (Van der Poel, 2018, p. 244).

Também por causa de seu pioneirismo não poderíamos deixar de mencionar Didática no cárcere I e II (SILVA, 2017, 2018), desenvolvida por um coletivo de cerca de 100 professores que atuam em prisóes na Zona Oeste de São Paulo e que se reuniram na Faculdade de Educação da USP com a coordenação do Prof. Roberto da Silva. Durante o 20 semestre de 2017 esse grupo buscou responder ao desafio de como trabalhar a Educação dentro de prisóes, tanto em regime fechado quanto em regime semiaberto, inclusive em centros de detenção provisória e em classes de escolas vinculadoras localizadas. A sistematização dessas propostas resultou no livro Didática no Cárcere: entender a Natureza para entender o ser humano e o seu mundo, produzido em tiragem limitada para que os professores envolvidos pudessem testá-lo em sala de aula, o que efetivamente foi feito durante o $1^{\circ}$ semestre de 2018. Dessa experimentação e dos ajustes feitos na metodologia resultou o Didática no Cárcere II, apresentado como a contribuição da Faculdade de Educação para que a Universidade de Sáo Paulo, juntamente com a Diretoria de Ensino responsável pelas escolas prisionais, efetivamente assumissem a responsabilidade pela implementação da educação nas unidades prisionais que estão situadas em seu território.

\section{Presos e presas se tornam autores e autoras}

Cárcere - a prisão funciona? - relatos de apenados sobre o encarceramento; Contos tirados de Mim: A Literatura no Cárcere Volumes 1 e 2; Gritos: a dramaturgia no cárcere e Mulheres Poéticas: a poesia no cárcere, todos publicados pela Editora Giostri ${ }^{5}$, são exemplos de produção dentro do próprio cárcere a partir de oficinas literárias desenvolvidas menos no sentido de transformar presos e presas em escritores e escritoras e mais no sentido de usar a literatura para transformar a vida de homens e de mulheres presas.

Outro exemplo que merece ser conhecido é o livro Vozes de um tempo - relatos e vivências de pessoas privadas de liberdade, com 130 poe- 
sias. Trata-se de uma obra coletiva escrita por nada menos que 112 presos de 33 unidades prisionais do estado do Rio Grande do Sul. A primeira edição, de 2012, selecionou 42 autores dentre 200 que se inscreveram; a segunda edição, de 2015, reuniu 60 presos e presas como autores. Neste caso específico, o objetivo, segundo o setor de Educação Prisional do Departamento de Tratamento Penal da Superintendência de Serviços Penais do Estado (Susepe), "é estimular a produção textual e fomentar a prática da leitura e da escrita nos estabelecimentos prisionais" [...] viabilizando o acesso à educação formal, educação complementar e a qualificação profissional, promovendo, assim, a inclusão social por meio do conhecimento."6

\section{Conclusão}

Como se depreende da leitura, do histórico, dos argumentos e dos referenciais teóricos utilizados neste texto, emerge um novo lócus de produção literária em espaços e contextos até entáo marcado pelo atraso, pelo abandono, pela precariedade e pela desumanidade dos tratamentos dados aos seus usuários. Atribuímos essa nova onda literária aos efeitos intergeracionais proporcionados pela educação e pelos novos usos que dela se faz, bem como da leitura e da escrita. As cartas escritas na prisão, sejam elas denúncias, comerciais, pessoais ou amorosas, revelam dimensóes difíceis de serem apreendidas por quem não vive tais realidades. Aprender a escrever cartas tem sido um dos motivos da busca pela alfabetização e pela elevação da escolaridade dentro das prisôes brasileiras. Essa motivação é compatível com o exercício de direitos básicos que não possam ser efetivados sem as competências leitoras e escritoras, o que corrobora ser a educação fundamento básico para o exercício de todos os demais direitos não atingidos pela sentença de condenação.

A remição pela leitura, apontada em seus estágios iniciais como meramente instrumental para diminuiçáo das penas, cada vez se mostra mais eficaz na abertura de novos horizontes para as pessoas presas e a produçáo literária é decorrência direta deste exercício.

Não consideramos, neste artigo, a produção de origem acadêmica resultante de pesquisas que falam sobre o preso, a prisão e suas práticas, 
que tem sido objeto de outros tipos de abordagem, mas indiretamente têm repercussão nesta chamada literatura carcerária, principalmente pelo envolvimento de professores, pesquisadores e alunos que atuam como monitores e estagiários.

Devemos ver com bons olhos essa nova onda literária, pois a exemplo do que ocorre no pântano com a flor de lótus, o ser humano consegue se superar nas condiçôes de maior adversidade.

\section{Notas}

${ }^{1}$ Fonte: http://www.scielo.br/pdf/ln/n62/a04n62.pdf

${ }^{2}$ A Editora Giostri foi a primeira a inaugurar um linha editorial especializada no tema: https:// lojavirtual.giostrieditora.com.br/index.php?route=product/category\&path $=140$

${ }^{3}$ Fonte: http://sbtinterior.com/videos/agente-penitenciario-ja-escreveu-tres-livros-de-poesia, 5937481724772.html

${ }^{4}$ Fonte: https://editoramultifoco.com.br/loja/product/diario-de-um-agente-penitenciario/

${ }^{5}$ Fonte: https://lojavirtual.giostrieditora.com.br/index.php? route=product/category $\&$ path=140

${ }^{6}$ Fonte: http://www.susepe.rs.gov.br/conteudo.php?cod_menu=4\&cod_conteudo=3258

\section{Referências}

AGAMBEN, G. O que resta de Auschwitz: o arquivo e o testemunho (Homo Sacer III). São Paulo: Boitempo Editorial, 2008. 175 p.

BRASIL. Ministério da Justiça. Departamento Penitenciário Nacional. Convocação no 01/2017. Projeto BRA/14/011. Fortalecimento da Gestáo Prisional no Brasil. Brasília, DF, 2017.

BRASIL. Ministério da Justiça e Segurança Pública. Portaria no 5, de 4 de Janeiro de 2018. Diário Oficial da República Federativa do Brasil. Brasília, DF, 2018,| Edição 5, Seção 1, p. 18-19-25.

ESTADO DE SÃO PAULO. Arquivo do Estado. Decreto $n^{\circ} 48.897$, de 27 de agosto de 2004. Dispóe sobre os Arquivos Públicos, os documentos de arquivo e sua gestão, os Planos de Classificação e a Tabela de Temporalidade de Documentos da Administração Pública do Estado de São Paulo, define normas para a avaliação, guarda e eliminação de documentos de arquivo e dá providências correlata.

HONNETH, A. Luta por reconhecimento: a gramática moral dos conflitos sociais. Trad.: Luis Repa. São Paulo: Ed. 34, 2003. 
MOREIRA, F. A.; SILVA, R. da. Açóes de incentivo à leitura e formação de leitores em estabelecimentos prisionais do Brasil: desafios e oportunidades. In: IV Congresso internacional de pedagogia social, 4., 2012, São Paulo. Proceedings online... Associação Brasileira de Educadores Sociais, Available from: <http://www.proceedings.scielo.br/ scielo.php?script=sci_arttext\&pid=MSC0000000092012000100029\&lng=en\&nrm=a bn>. Acess on: 17 Jan. 2019.

PIRES, T. R. O.; FREITAS, F. (Org.). Vozes do Cárcere: ecos da resistência politica. 1. ed. Rio de Janeiro: Kitabu, 2018. v. 1.480 p.

POLI JUNIOR, Ovidio. A pena e o cadafalso: observaçóes sobre a literatura carcerária relativa ao período do Estado Novo. 2009. Tese (Doutorado em Literatura Brasileira) - Faculdade de Filosofia, Letras e Ciências Humanas, Universidade de São Paulo, São Paulo, 2009. doi:10.11606/T.8.2009.tde-01122009-112205. Acesso em: 2019-03-18.

RICOEUR, P. A memória, a história, o esquecimento. Campinas, SP: Editora Unicamp, 2007.

SELIGMANN-SILVA, M. Literatura de testemunho: os limites entre a construção e a ficção. Letras, Revista do Mestrado em Letras da UFSM. Santa Maria, RS, UFSM; CAL, n. 16, jan./jul. 1998, pp. 9-37.

SELIGMANN-SILVA, M. (Org.) História, Memória, Literatura. O testemunho na era das catástrofes. Campinas: Editora da UNICAMP, 2003. 555 p.

SELIGMANN-SILVA, M.. Escritas da violência. Vol I. O testemunho, Orgs. Márcio Seligmann-Silva, Jaime Ginzburg, F. Hardman, Rio de Janeiro: 7 Letras, 2012. 289 p.

SILVA, R. da. A eficácia sócio-pedagógica da pena de privação da liberdade. 2001. Tese (Doutorado em Educação). Faculdade de Educação, Universidade de São Paulo: São Paulo, 2001.

SILVA, R. da. O Direito à Educação de Pessoas em Regimes de Privação da Liberdade. In: Revista de Ciências da Educação. Centro Universitário Salesiano de São Paulo UNISAL. Programa de Mestrado em Educação. Americana, SP, Ano XII, n. 22. pp. 199- 222, 2010.

SILVA, R. da. Os filhos do Governo: a formação da identidade criminosa em crianças orfãs e abandonadas. São Paulo: Ática, 1997.

SILVA, R. da. Didática no Cárcere: entender a natureza para entender o ser humano e o seu mundo. São Paulo: Giostri, 2017.

SILVA, R. da. Didática no Cárcere II: entender a natureza para entender o ser humano e o seu mundo. São Paulo: Giostri, 2018. 
TIN, Emerson. Em busca do "Lobato das cartas": a construção da imagem de Monteiro Lobato diante de seus destinatários. 2007. 547f. Tese (doutorado) - Universidade Estadual de Campinas, Instituto de Estudos da Linguagem, Campinas, SP. Disponível em: <http:/www.repositorio.unicamp.br/handle/REPOSIP/270302>. Acesso em: 11 set. 2018.

VAN DER POEL, Maria Salete. Vidas aprisionadas: relatos de um prática educativa. Porto Alegre: Oykos, 2018.

VASQUEZ, E. L. Ciência Penitenciária no Brasil Império: Disciplinar para construir a imagem da nação civilizada. Tese (Doutorado). São Paulo: PUC/SP, 2013.

Recebido em 25 jan. 2019 / Aprovado em 20 mar. 2019

\section{Para referenciar este texto:}

SILVA, R.; PASSOS, T. B.; MARQUES, M. A. Literatura carcerária: educação social por meio da Educação, da escrita e da leitura na prisão. EccoS - Revista Científica, São Paulo, n. 48, p. 35-50. jan./mar. 2019. Disponível em: <https://doi.org/10.5585/ EccoS.n48. 12392>. 